\title{
Evaluation of watershed water quality risk reduction after earthquake disasters
}

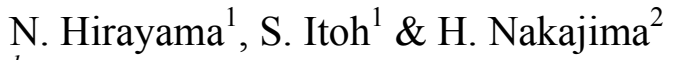 \\ ${ }^{I}$ Department of Environmental Engineering, Kyoto University, Japan \\ ${ }^{2}$ Fire and Disaster Management Agency of the Ministry of Internal \\ Affairs and Communications, Japan
}

\begin{abstract}
In this study, a procedure is established for evaluating the watershed water quality risk reduction after earthquake disasters. Using the method of scenario planning, the risk scenario of watershed water quality in the aftermath was developed as a model of decision tree that can describe the uncertainty events, decision-making and emergency response. Using the watershed water quality risk scenario and the watershed flow model based on box model with mass balance, a model for evaluating the watershed water quality risk was developed. Numerical simulation analysis for estimating the watershed water quality risk in Lake Biwa and Yodo River basin after an earthquake disaster was conducted. Furthermore, the effectiveness of countermeasures against watershed water quality risk was estimated. As a result, it was pointed out that the comprehensive countermeasures with cooperation of stakeholders in the watershed water quality, including information sharing, would reduce considerable watershed water quality risk. Consequently, it was indicated that implementation of the cooperative countermeasures for preservation of watershed water quality for water supply with stakeholders related to watershed water quality would reduce watershed water quality risk in the aftermath effectively.

Keywords: watershed water quality risk, scenario planning, stakeholders, countermeasures against watershed water quality risk, information sharing, numerical analysis.
\end{abstract}




\section{Introduction}

After an earthquake disaster, water supply utilities, which are located at the down stream of the river, would have vulnerability in qualitative risk of water resources quality for water supply such as raw water contamination caused by an effluent spill out public waters from damaged sewerage and wastewater system located at the upper stream of the river. The risks and countermeasures for water supply and sewerage systems after earthquakes have been examined based on the experience of the 1995 Hanshin-Awaji Earthquake and the 2004 Mid Niigata Prefecture Earthquake from the viewpoint of watershed risk management [1]. In order to secure water resource for water supply after earthquake disasters, it is indispensable to establish the river basin risk and crisis management. The purpose of this study is to evaluate the watershed water quality risk on emergency response stage after earthquake disasters for watershed risk/crisis management.

For this purpose, using scenario planning, that is one of approach of risk management, the risk scenario of watershed water quality after earthquake was developed as a model of decision tree that can describe the uncertainty events, decision-making and emergency response in the aftermath. From the viewpoint of the preservation of water resources quality for water supply, the effectiveness of countermeasures against water quality risk for watershed water quality risk mitigation and reduction was estimated using numerical analysis model with water quality risk scenario.

\section{Evaluation of watershed water quality}

In this study, watershed water quality risk was considered a possible threat to social and economic activities and civil life from the viewpoint of water use and public health in river basin. In the field of water supply, measures for water supply utilities and emergency response in water quality accident have been examined in the implementation guidelines and procedures for water contamination accident [2]. In the field of sewerage systems, countermeasures against earthquake disasters have been conducted systematically for water quality risk mitigation and reduction [3]. In addition, the environmental risk management procedures have been examined in the field of manufacturing industries, in specially electrical and electronic industry [4].

On the other hand, the Ministry of Health, Labour and Welfare and the Ministry of Land, Infrastructure, Transportation and Tourism examined an evaluation of watershed water quality risk and countermeasures for its risk reduction and avoidance in order to conduct the security of civil health and sanitary, the prevention of water contamination in river basin and the prevention of public health in emergency [5]. From the viewpoint of watershed risk and crisis management, it is important to execute countermeasures for risk reduction in quality of water resources with cooperation of stakeholders; such as waterworks, sewerage utilities, and manufacturers. In addition, it is necessary to 
develop the evaluation procedure of watershed water quality risk as an assessment tool of risk reduction in watershed risk management.

From the viewpoint of evaluation of water quality risk, the procedure of critical evaluation based on risks of infectious disease has been examined. Kaneko developed an evaluation procedure for risk of waterborne infectious disease through drinking water [6]. The case studies on health risk related to drinking water were carried out from the viewpoint of risk management of tap water quality [7, 8]. Quantitative evaluation of risk of intake interruption and suspension of water supply, caused by water contamination, was developed [9]. However, the implementation of watershed water quality risk management could not complete PDCA (Plan-Do-Check-Action) Cycle based on the effectiveness evaluation of risk reduction of watershed risk and crisis management for preservation of water resources for water supply.

In this study, therefore, evaluation procedure for watershed water quality risk reduction for preservation of water resources quality for water supply is developed. The purpose of this study is to develop a procedure for watershed water quality risk assessment of risk reduction and mitigation, and the effectiveness of risk reduction could be estimated according to the relative evaluation of probability of risk scenario. In addition, we would deal with a hazard, of which stakeholders related water quality risk in Lake Biwa and Yodo River, could make a common disaster image, and trigger event of watershed water quality risk would be assumed as earthquake disaster, in specially Kyoto Hanaore Active Faults Earthquake. Figure 1 shows the locations of the Lake Biwa and Yodo River Basin and the Kyoto Hanaore Active Faults [10].

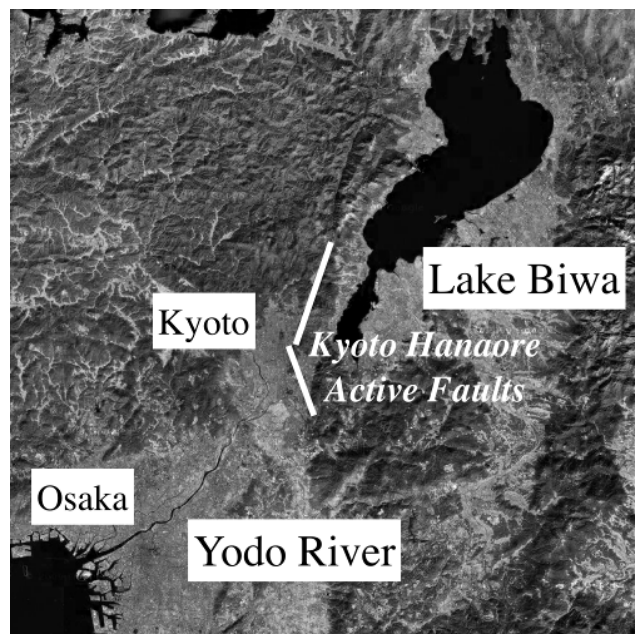

Figure 1: Lake Biwa and Yodo River basin and the Kyoto Hanaore Active Faults. 


\section{Evaluation model for watershed water quality risks on earthquake disasters}

\subsection{Watershed water quality risk scenario}

\subsubsection{Scenario planning}

Scenario planning is a strategic planning method that allows suitable decisionmaking in environments of high uncertainly by hypothesizing multiple scenarios that could occur $[11,12]$. Here we define scenarios as multiple visions of the future with differing structures that each has considerable possibility of occurring. The probability of occurrence of each scenario is not included because these scenarios are not approached from a probability theory perspective. However, uncertainty accompanies crisis management, and as this uncertainty increases, decision-making during crisis becomes increasingly difficult. Thus, Scenario planning is a useful tool for strategic planning for uncertain conditions.

First, we conduct an even more precise analysis of those scenario drivers, and create multiple scenarios related to external environments that could occur in the future. Scenario drivers are handled as discrete items for whether some event occurs or does not occur. And, we modelled the structure of the change of these scenario drivers called a scenario logic model.

In this manner, with countermeasures and strategic planning for water quality risks in watershed during crises as the objectives, we create scenario logic models by determining the external environment, which includes the realms of water supply, sewerage, manufacturing industries that handle chemicals and river administrations, and using decision tree analysis. One value of scenario planning is to deepen the understanding of project environment changes by participants and increase their decision-making skills. In other words, it promotes organizational learning. From the perspective of watershed risk management that promotes the management of risks for an entire watershed, we employed a workshop method, which generates output through intellectual interaction, including the deliberations and focused thinking of the participants [13]. We conducted separate workshops with participants from the staffs of the Osaka Prefectural Waterworks Bureau, the Kyoto City Waterworks Bureau, Shimadzu Corporation, and the Yodo River Office of the Ministry of Land, Infrastructure, Transport and Tourism.

\subsubsection{Water quality risk scenarios based workshop method}

In the design of these workshops, we referred to procedures used in previous workshop [14], and designed workshops that could advance the extraction, organization and systemization of ideas in a form that suits scenario planning.

Next, we analyzed the causal relationships, linkages and interactions between the extracted scenario drivers. Combining the scenario drivers, we created a scenario logic model through decision tree analysis [15]. In this result, 'Latent water quality risks exist' was concluded from the 'Damage to water purification facilities,' 'Electricity supply stops' and 'Yodo River is polluted by untreated wastewater' events. 
Water quality risk scenarios after the Kyoto Hanaore earthquakes for each of the fields were developed. From the perspective of water circulation in the watershed, from water supply resources and the people who demand the water to sewers and rivers, following timelines after the earthquake of manufacturing businesses and water treatment organizations upstream as well as water supply organizations located down stream in the watershed, we were able to summarize water quality risk scenarios for each domain based on causal relationship, linkages and interactions of the events that occur in the scenarios. Here, we could summarize the water quality risk scenarios for each domain and extracted the scenario drivers that are related to watershed water quality risks. In other words, scenario drivers and events that could not be confirmed to have causal relationships with watershed water quality risks were excluded. In this way, a decision tree with 'the occurrence of the Kyoto Hanaore Earthquakes' as the starting point and that concludes 'there are latent water quality risks', was developed as a scenario model for the water quality risks in a watershed.

\subsection{Lake Biwa and Yodo River watershed flow model}

In this research, using a box model, a watershed flow model that quantitatively analyzes the flow of water and substances in the Lake Biwa and Yodo River watershed was developed. In short, as shown in Figure 2, the Lake Biwa and Yodo River basin was divided into boxes and calculated material flows between the boxes. In addition, since the objective of this research is to evaluate the risk to watershed water quality when an earthquake occurs, along with volumes of substances, transmission between boxes would be in accordance with the following conditions and information as shown in Table 1.

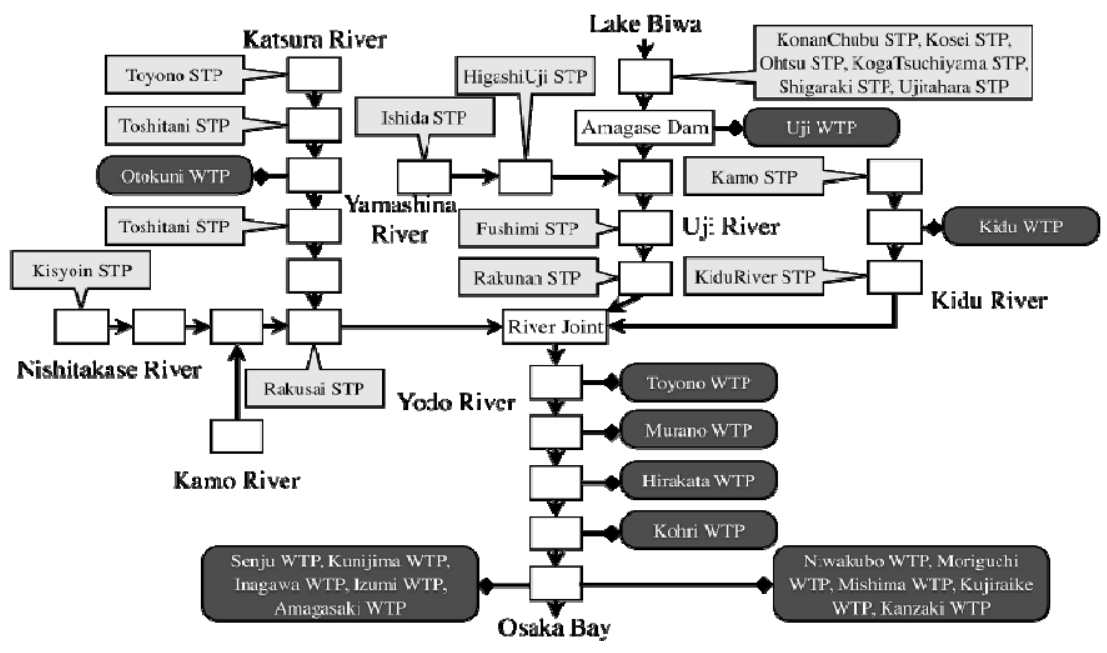

Figure 2: $\quad$ Lake Biwa and Yodo River watershed flow model. 
Table 1: Conditions and information transmitted between boxes of watershed flow model.

Water pollution from manufacturing industries into public waters

Water pollution from manufacturing industries into public scwcrage system

Contamination of substances that cannot be treated by wastewater treatment

Effluent without treatment or with only primary treatment

Reactions of both a carp sensors and fish in sand settling basin

Information about the status of wastewater treatment

Sharing water quality monitoring information with stakeholders

\subsection{Evaluation Model for watershed water quality risk}

The outline of evaluation model for watershed water quality risk is shown in Figure 3. Here, by combining the watershed flow model with the water quality risk scenario model for each field, a watershed water quality risk evaluation model was developed. The results of numerical analysis using the water quality risk scenarios are discrete values of whether or not events occur, and quantitative values cannot always be obtained. Thus, connecting the water quality risk scenario models and the watershed flow model using parameters for events that occur in the water quality risk scenario models, a watershed water quality risk evaluation model, which would describe quantitative estimation, was developed.

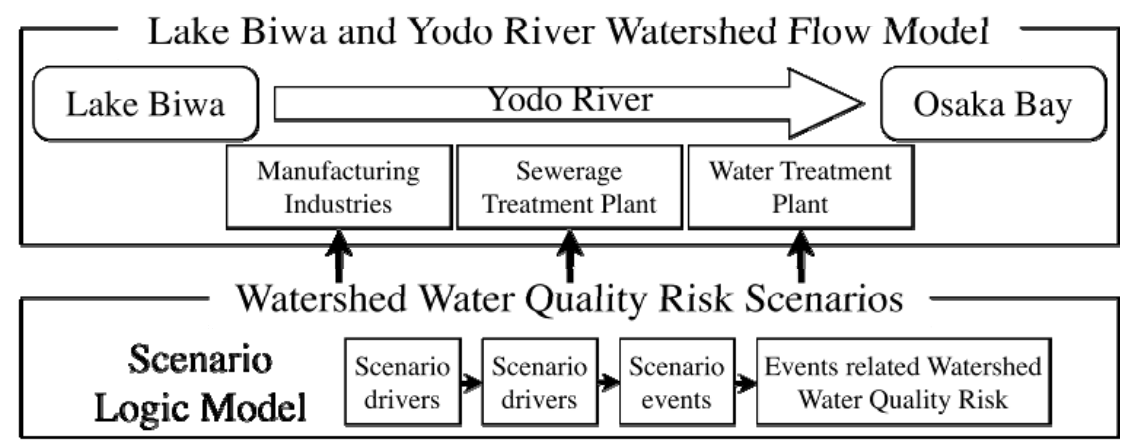

Monte Carlo simulation method

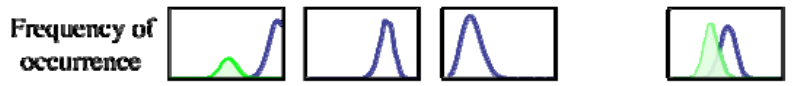

Scenarios of Water Quality Risk Countermcasures : increase/decrease of frequency of occurrence

Figure 3: $\quad$ Outline of evaluation model for watershed water quality risk. 
This paper would deal with zinc as chemical measurements subject to watershed water quality risk evaluation, and quantitative evaluation of the effectiveness of the countermeasures for watershed water quality risk reduction was conducted using the developed watershed water quality risk evaluation model. In short, according to numerical analysis with a Monte Carlo simulation method, the water quality risk countermeasures, taken separately in each field, were evaluated to determine the extent that each contributes to watershed water quality risk reduction and its mitigation effectiveness.

\section{Evaluation of risk reduction on measures against watershed water quality risk}

\subsection{Effectiveness evaluation of water quality risk reduction}

The effectiveness evaluation of water quality risk reduction was conducted using the frequency of the occurrence of the scenario drivers, their events and the success of emergency responses to them, as shown in Table 2, as standards. In this research, the implementation of water quality risk countermeasures in each sector according to changes in the frequency of events was described. In summary, by implementing water quality risk countermeasures, the frequency of events decreased or the frequency of countermeasures successes increased.

Table 2: $\quad$ Frequency of occurrence of the scenario drivers.

\begin{tabular}{|c|c|}
\hline V & very likely (more than $90 \%)$ \\
\hline IV & likely $(65 \% \sim 90 \%)$ \\
\hline III & medium likelihood $(35 \% \sim 65 \%)$ \\
\hline II & unlikcly (10\% 35\%) \\
\hline I & very unlikely (less than $10 \%)$ \\
\hline
\end{tabular}

Since our purpose is to evaluate the effectiveness of water quality risk countermeasures and policies to mitigate water quality risks in a watershed, we did not seek absolute evaluations of water quality risks, but rather, we sought water quality risk mitigation effectiveness through relative evaluations. In short, setting the watershed water quality risk evaluation as $100 \%$ before the implementation of water quality risk mitigation countermeasures and policies, we then calculated watershed water quality risk evaluations after the implementation of countermeasures as a percentage.

Furthermore, in this study, since we focused on water quality risks in a watershed, we only considered evaluation items related to water quality risk. Since there is the possibility that water-soluble zinc compounds could suddenly 
flow in after earthquake disasters, it is difficult to predict their concentrations. For this reason, we evaluated the potential exposed population by calculating the supplied population and the rate of removal, and then calculating the amount of potential exposure in the watershed from the flow amount of zinc water-soluble compounds and the potential exposed population.

\subsection{Scenarios of water quality risk countermeasures}

In this paper, water quality risk countermeasures that are currently being implemented in each sector, in the planning stage or currently not being implemented were evaluated. The watershed water quality risk mitigation effectiveness of 12 such countermeasures and policies was estimated. In addition, comprehensive scenario for countermeasures implemented by sectors independently that includes the multiple independent water quality risk mitigation countermeasures of each sector for the watershed as a whole was evaluated. And a comprehensive scenario for countermeasures implemented with coordination between sectors was developed. Table 3 shows these water quality risk countermeasures scenarios for evaluation.

Table 3: Countermeasures scenario for watershed water quality risk reduction.

\begin{tabular}{|c|c|c|c|c|}
\hline No. & Content & Manufacture & Sewerage & Water Supply \\
\hline MI & Prevention of fall of material equipments in manufacturing industries & 1 & & \\
\hline M2 & Prevention of effluent in manufacturing industries & 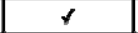 & & \\
\hline si & Measures on intenuption of service in sewerage system & & $\checkmark$ & \\
\hline S2 & Preservulion of capability of pumping stalion in sewerage syslem & & $\checkmark$ & \\
\hline $\mathbf{S 3}$ & Preservalion of capability of sewerage treatment & & $\checkmark$ & \\
\hline \$4 & Information sharing with staketholders on river downstream & & $f$ & \\
\hline WI & Measures on internuption of service in water supply system & & & 1 \\
\hline W2 & Change whece intake in water supply system & & & 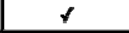 \\
\hline w3 & Incake interruption in water supply system & & & $\checkmark$ \\
\hline $\mathbf{w 4}$ & Preservalitu or capability or purificalion lacilities in waler treadment system & & & $\vec{r}$ \\
\hline w5 & 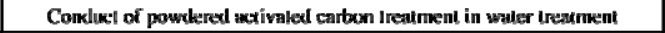 & & & $\checkmark$ \\
\hline W6 & Suspension of water transmission facilities in water supply system & & & 1 \\
\hline MA & Comprehensive measures in manufacturing industries (MI \& M2) & 1 & & \\
\hline SA & Comprehensive meusures in sewernge system (S1, S2, S3, \& S4) & & $\checkmark$ & \\
\hline WAI & Counternensures without quantitative risk measures (W1, W2, W4, \& W6) & & & $\checkmark$ \\
\hline WA2 & Comprehensive measures in waler supply (W1, W2, W3, W4, W5, \& W6) & & & $\checkmark$ \\
\hline AI.I.I & Coopernlive mensures without quanlitalive risk mensures (expect W3 \&W6) & $\checkmark$ & $\checkmark$ & $\checkmark$ \\
\hline ALL2 & Cocperative measures including quantitalive risk measures & $\checkmark$ & $\checkmark$ & $f$ \\
\hline
\end{tabular}

Furthermore, we used the frequencies of events as parameters for quantitative analysis in the watershed water quality risk scenario models in which water quality risk countermeasures and policies were implemented. Moreover, evaluation results based on the water quality risk countermeasures plans of each organization and interviews with the personnel involved in them should be applied to the evaluation of watershed water quality risk reduction. 


\subsection{Results of quantitative evaluation of watershed water quality risk reduction}

The result of effectiveness evaluation of watershed water quality risk mitigation for water-soluble zinc compounds is shown in Figure 4. In case of water-soluble zinc compounds, watershed water quality risk was estimated as amount of potential exposure. According to this result, countermeasures in the manufacturing industries sector would decrease the amount of effluent and reduce the watershed water quality risk of potential exposure. It was indicated that for chemical substance which be considered as point source pollution on earthquake disasters, measures in manufacturing industries sector would be contributed to risk reduction of watershed water quality. In water sector, measures for preservation of capacity of purification facilities after earthquakes would have sufficiency effectiveness of the watershed water quality risk reduction.

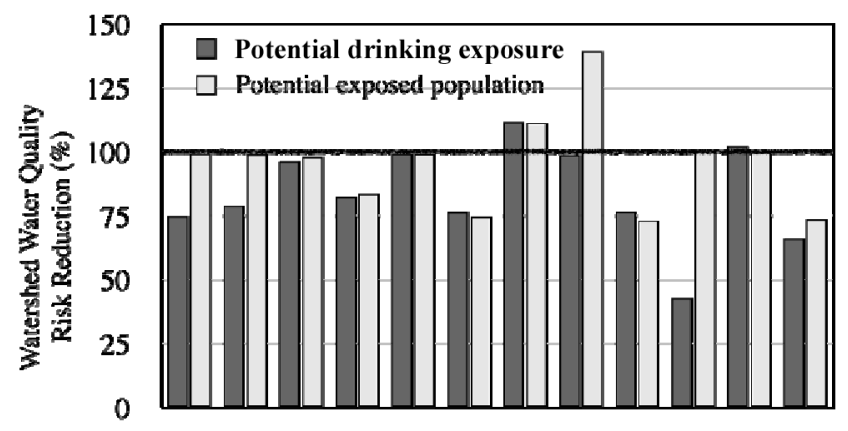

$\begin{array}{llllllllllll}\text { M1 } & \text { M2 } & \text { SI } & \text { S2 } & \text { S3 } & \text { S4 } & \text { W1 W2 } & \text { W3 } & \text { W4 } & \text { W6 }\end{array}$

Figure 4: $\quad$ Result of effectiveness evaluation of watershed water quality risk mitigation for water-soluble zinc compounds.

Figure 5 shows the result of watershed water quality risk reduction in comprehensive scenario of countermeasures for water-soluble zinc compounds. Comprehensive countermeasures in the manufacturing industries sector and sewerage sector would reduce the watershed water quality risks more effectively than individual countermeasures. In water supply sector, watershed water quality risk reduction in countermeasures scenario without quantitative risk mitigation was estimated $43.1 \%$, and the scenario with quantitative risk mitigation could decrease $69.5 \%$ of the watershed water quality risks. The countermeasures scenario including quantitative risk mitigation would increase the water suspension population to $178 \%$. This result indicates that water quality risk avoidance due to emergency response for interruption in supply could reduce the watershed water quality risk effectively. Also, it was pointed out that the comprehensive countermeasures with cooperation of stakeholders in the watershed water quality, including information sharing, would reduce considerable watershed water quality risk. 


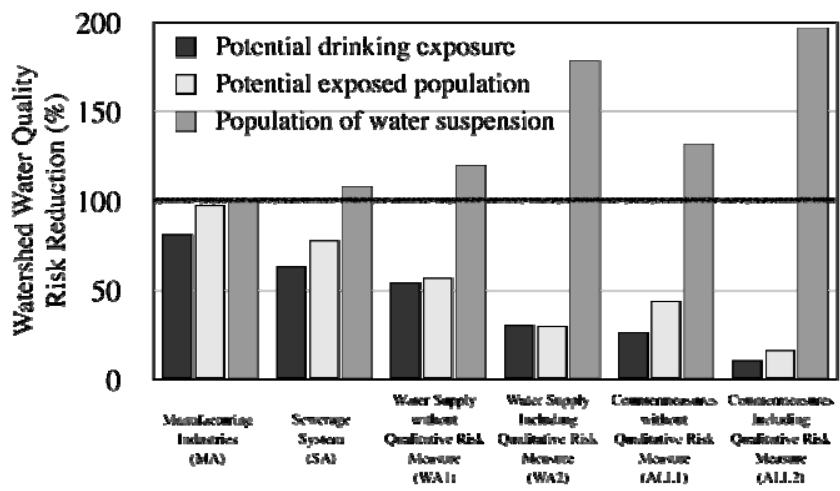

Figure 5: Evaluation result of watershed water quality risk reduction by comprehensive countermeasures for water-soluble zinc compounds.

\subsection{Discussion}

In this paper, using the watershed water quality risk scenario model, the watershed water quality risk evaluation model was developed. Using the developed risk evaluation model, numerical simulation analysis for watershed water quality risk of water-soluble zinc compounds was conducted, and the effectiveness of the countermeasures for watershed water quality risk reduction after earthquake was estimated. It was pointed out that comprehensive countermeasures with cooperation of stakeholders in the watershed water quality would reduce the watershed water quality risks more effectively than individual measures in each sector. Therefore, it was indicated that implementation of the cooperative countermeasures for preservation of watershed water quality for water supply with stakeholders related to watershed water quality would reduce watershed water quality risk in the aftermath effectively.

An evaluation procedure for watershed water quality risk reduction for preservation of water resources quality for water supply was established. It is our belief that this evaluation procedure could be a risk assessment tool that risk mitigation effectiveness of countermeasures against water quality risk is evaluated. Therefore, it was concluded that watershed water quality risk reduction required not only risk assessment but also implementation of watershed water quality risk management on the basis of PDCA (Plan-DoCheck-Action) Cycle.

In this watershed water quality risk scenario model, scenario drivers include emergency response and measures related to quantitative risk, such as intake interruption and suspension of water transmission. In this paper, therefore, the water suspension population caused by quantitative risk mitigation was estimated. This result indicates that watershed water qualitative risk could involve a trade-off between qualitative risk and quantitative risk, which if the amount of drinking exposure and population exposure considered as qualitative 
risk reduce, the population of water suspension considered as quantitative risk increase. In emergency response in the aftermath, a dilemma between qualitative risk and quantitative risk in measures, policies, and emergency response could be caused by the reduction of watershed water quality risk. Thus, it is necessary to establish watershed water qualitative risk and crisis management as a watershed unity and to improve faculties for emergency response by drill and training.

\section{Conclusions}

A procedure for the estimation of watershed water quality risk reduction was established based on numerical analysis, and the effectiveness of the countermeasures for watershed water quality risk mitigation was examined. From this study, we reached the following important conclusions:

1) Using scenario planning, the risk scenario of watershed water quality after earthquake disasters was developed. Furthermore, an evaluation model for watershed water quality risk reduction based on the risk scenario was developed.

2) An evaluation of the effectiveness of the countermeasures against watershed water quality risk in the aftermath was conducted using the developed evaluation model for watershed water quality risk reduction.

3) It was pointed out that the comprehensive countermeasures with cooperation of stakeholders in the watershed water quality, including information sharing, would reduce considerable watershed water quality risk.

4) It was revealed that a dilemma between qualitative risk and quantitative risk in measures, policies, and emergency response could be caused by the reduction of watershed water quality risk in emergency response.

5) It was indicated that implementation of the cooperative countermeasures for preservation of watershed water quality for water supply with stakeholders related to watershed water quality would reduce watershed water quality risk in the aftermath effectively.

\section{Acknowledgements}

We wish to thank the Osaka Prefectural Waterworks Bureau, the Kyoto City Waterworks Bureau, Shimadzu Corporation, and the Yodo River Office of the Ministry of Land, Infrastructure, Transport and Tourism for participation in scenario planning workshop. This work was supported by Grants from Nippon Life Insurance Foundation and the Kyoto University Global COE Program "Global Center for Education and Research on Human Security Engineering for Asian Megacities."

\section{References}

[1] M. Akiba, Earthquake Risk and its Countermeasures for Water Supply and Sewerage Systems, Jour. of the National Institute of Public Health, 56(1), pp.9-15, 2007. 
[2] Japan Water Works Association, Guidelines for Waterworks Technical Management, 2006.

[3] Ministry of Health, Labour and Welfare, Government of Japan, Report on Measures to Preserve Water Resources for Water Supply, 2007.

[4] Research Group on Risk Management in Electrical and Electronic Manufacture, Guidelines on Environmental Risk Management Using ISO 14001, 1, 2007.

[5] Ministry of Health, Labour and Welfare, Government of Japan, FY2005 Report on Cooperative Measures for the Comprehensive Preservation and Improvement of Watershed Water Quality - Cooperative Measures for Water Quality Risk in Emergency, 2006.

[6] M. Kaneko, Evaluation of Risk of Waterborne Infections Disease, Measures on Pathogenic Microorganisms in Water Supply System, pp. 219237, 2006.

[7] T. Yamada, M. Akiba, M. Asami, M. Shimazaki, \& S. Kunikane, Case Study on Analysis of Health Crisis Related to Drinking Water During the Last 10 Years, Proc. of 58th Annual Conference on JWWA, pp.650-651, 2007.

[8] T. Yamada, M. Akiba, M. Asami, H. Yukimoto, T. Ishida, \& H. Kuroko, Classification and Risk Evaluation of Health Crisis Related Drinking Water, Proc. of 59th Annual Conference on JWWA, pp.640-641, 2008.

[9] Y. Sakakibara, H. Kato, S. Kannou, K. Gotoh, Y. Nakayama, \& Y. Shimizu, Study on Countermeasures on Risk of Intake Interruption and Suspension of Water Supply in Water Utilities, Proc. of 58th Annual Conference on JWWA, pp.648-649, 2007.

[10] Central Disaster Prevention Council, Cabinet Office, Government of Japan, Estimation of Damage caused by the inland earthquakes in Chubu and Kinki Districts, 2007.

[11] K. Heijdem R. Bradfield, G. Burt, G. Cairns, \& G. Wright, The Sixth Sense Accelerating Organizational Learning with Scenarios, John Wiley \& Sons, Ltd., 2002.

[12] K. Ikeda \& M. Imaeda, Practical Scenario Planning, Toyo Keizai, 2002.

[13] T. Nakano, Facilitation Revolution, Iwanami Press, 2003.

[14] N. Hirayama, K. Kobayashi, K. Komiyama, M. Mihara, T. Okamoto, H. Hayashi, \& S Itoh, A Planning of Comprehensive Crisis Management for Water Supply Authorities Involving Staffs - A Case Study of Reinforcement of Crisis Management for Hanshin Water Supply Authority, Environmental \& Sanitary Engineering Research, 22(2), pp.33-42, 2008.

[15] N. Hirayama, S. Itoh, \& H. Nakajima, Evaluation of Watershed Water Quality Risk Reduction on Crises Using Scenario Planning Approach, Environmental \& Sanitary Engineering Research, 22(3), pp.27-34, 2008. 